\title{
REFLEXÃO E QUESTIONAMENTO DA CONSTRUÇÃO DO PROFISSIONAL BIBLIOTECÁRIO NO BRASIL
}

\author{
REFLECTION AND QUESTIONING ON THE CONSTRUCTION OF PROFESSIONAL \\ LIBRARIES IN BRAZIL
}

\author{
Pedro Paulo Almeida Martins ${ }^{2}$
}

RESUMO: O presente artigo visa discorrer sobre uma reflexão do profissional bibliotecário no Brasil. Com o intuito de destacar sob a atuação do profissional da informação, diante de uma Biblioteca, Centro da Documentação e Unidade de Informação. Visa contextualizar a importância da adaptação através das mudanças e transformações ocorridas nas Tecnologias da Informação para a atuação, exercício e o reconhecimento do Profissional bibliotecário brasileiro.

Palavras- chave: Transformação. Construção. Profissional da Informação.

ABSTRACT: This article aims to discuss a reflection of professional librarians in Brazil. In order to stand out under the role of the information professional, in front of a Library, Documentation Center and Information Unit. It aims to contextualize the importance of adaptation through the changes and transformations that have taken place in Information Technologies for the performance, exercise and recognition of the Brazilian Professional Librarian.

Keywords: Transformation. Construction. Information Professional.

\section{INTRODUÇÃO}

O trabalho apresentado, tem como objetivo, demonstrar que, o mercado de trabalho do bibliotecário mudou com o desenvolvimento de novas tecnologias e a sociedade também tem necessidades por isso seu trabalho e expertise são reconhecidos, porém, não entrando em extinção. Embora o bibliotecário esteja inserido no sindicato trabalhista como autônomo ele encontrará mais oportunidades no serviço público para atuação. Neste caso se considera a importância da orientação profissional tanto para garantir o desempenho

\footnotetext{
${ }^{2}$ Bibliotecário Documentalista do Instituto Federal de Rondônia- IFRO. Acadêmico do curso Direito na Faculdade Católica de Rondônia- FCR e graduando em Ciências Sociais na Universidade Federal de Rondônia - UNIR, Porto Velho, Brasil; Pedro Paulo Almeida Martins, Bibliotecário, tecnólogo em Gestão pública, 4 titulações de pós-graduado: Especialista em Gestão Pública, metodologia do ensino superior em Língua Portuguesa, Biblioteconomia e MBA em Governança e Gestão Administrativa, , E-mail: pedropaulogestorpublico@gmail,com, currículo Lattes: http://lattes.cnpq.br/3951670487194507 Orcid: https://orcid.org/oooo-ooo2-349o-8784
} 
profissional de pessoal qualificado como para assegurar e proteger os interesses da comunidade e dos cidadãos que a procuram a biblioteconomia é uma divisão do campo da ciência da informação. É uma área da ciência que inclui cursos ou disciplinas e especialistas. Pode ser uma área que inclui pesquisa científica e prática profissional.

Devido aos problemas que apresenta e dos métodos para resolvê-los, problemas e opiniões, a área se apresentam como um campo teórico de estudo levar uma reflexão sobre a transformação ocorrida pelo profissional bibliotecário no Brasil. Apontando levantamentos e questionamentos da trajetória deste profissional mediador, que tanto contribui para agregar valores na educação, que gera formadores de opinião, dentro de uma biblioteca, com o meio da leitura. Então, o bibliotecário tem como foco principal disponibilizar fontes de informações segura e confiável para o usuário que venha necessitar de um serviço de qualidade, disponível por um profissional bibliotecário. E destaca, no transcorrer do texto, as mudanças nas tecnologias de informação, que não só o bibliotecário passa. Como também o usuário acaba passando, por uma mudança e transformação, devem ter um Quem define o bom senso? e ser adaptados, com o devido tempo. Inicia, aliando uma abordagem da ética do profissional bibliotecário, suas responsabilidades e respeito para não infringi-la. Faz também, uma trajetória histórica de todo o marco da importância do profissional bibliotecário, que desde a formação e criação da primeira escola de biblioteconomia no Brasil, seu contraste que acompanha este profissional até hoje, neste tempo de mudança que é o tempo moderno. Há de notar que inclusive mais lá na frente, demonstrará que o profissional da informação sofrerá transformações, que será acompanhada de adaptações, pois as tecnologias da informação surtirá um grande efeito de importância na vida profissional. Certamente, emprego do termo; que a globalização veio a tona, para criar tendências. Que influencia, interligar, integrar e gerar padrões de vida na sociedade, pois tudo hoje está instantâneo.

\section{O PRESSUPOSTO DA ÉTICA DO PROFISSIONAL BIBLIOTECÁRIO NO BRASIL, COMO UMA RESPONSABILIDADE A SER SEGUIDA, PARA A CONSTRUÇÃO DA PROFISSÃO}

Antes de mais nada, quando falamos sobre construção de um profissional, logo iniciarmos uma reflexão a partir de um ponto de vista da ética profissional, pois quando 
um indivíduo que tenha de berço princípios morais e virtudes, já no egresso da sua formação da sua vida decerto, sem dúvida, será um bom profissional. Contextualizamos sobre o profissional da informação, que não há nada melhor, corroborar a então ética. Que segundo o dicionário Aurélio: (Chico Buarque de Holanda Ferreira; ano 200o, p.300): A ética é estudo dos juízos de apreciação referentes à conduta humana (entre o bem e o mal). $\mathrm{Na}$ base do conhecimento adquirido, tenho como concepção que Ética Profissional; seria uma junção de elementos de padrão ou norma de condutas prevista em lei que dependendo do ato de descumprimento ou infração gerará sanções ou punições de acordo com grau acometido, ou seja, essa ética deve ser posta em prática em plena função de exercimento de qualquer carreira profissional, para a ordem e progresso, não só da própria carreira profissional, como para o bem de toda a sociedade em geral, no Brasil, será de grande importância o uso, para a construção do profissional bibliotecário, já segundo consta:

No site do Conselho Regional de Biblioteconomia 8o Região; O Código de Ética Profissional do Bibliotecário, como já dito, que não é de forma diferenciada tanto com a outra concepção como este embasado que está na legislação, é evidente que tem a mesma finalidade, com diretrizes a seguir, que vai no seguinte encontro com Art Io O Código de Ética Profissional, tem por objetivo fixar normas e conduta para os profissionais em biblioteconomia no desempenho da profissão.

A temática trazida à tona é muito ampla, resumindo o bibliotecário, assim como rege o código de ética profissional tem seus direitos e deveres, são vários parâmetros, mas dentre eles, os de maiores e piores, importância que vale ressaltar, que possivelmente irá diminuir ou sanar, talvez uma infração da quebra da ética profissional são: I) Deve-se manter atualizado e zelar sobre as novas legislações referente a categoria, deve-se prestar bom atendimento ao usuário com respeito e cortesia no limite; ser leal no ambiente de trabalho; evitar criticas difamatórias a profissionais ou colegas de trabalho. 2) Jamais violar o sigilo profissional; Nunca usar má-fé nas interpretações de conteúdos e documento contido na instituição; $\mathrm{O}$ que deve notar no 'item' do Art. $7^{\circ}-\mathrm{O}$ bibliotecário deve, em relação aos usuários, observar a seguinte conduta: c) ater-se ao que lhe compete na orientação técnica da pesquisa e na normalização do trabalho intelectual. Contudo, isso levou a instigar-me ideias e suposições na minha percepção que foi do tipo: Se um usuário chegasse ao bibliotecário e consultasse uma orientação através de informação de como fazer uma bomba de coquetel Molotov ou qualquer artefato explosivo de cunho terrorista, 
qual seria o posicionamento ético do profissional bibliotecário, daria a informação, e quebraria a ética profissional, ou respeitaria as normas e condutas imposta pela ética profissional, apesar que hoje entrou em decréscimo, o aumento de pesquisas no google, pois bem, sabendo que essa informação dependendo da finalidade dessa engenharia social (artefato), poderá gerar danos e sequelas para vidas de uma sociedade, eis a questão que remete dúvidas.

Já, portanto falando-se muito em ética, vale frisar a ideia a seguir que inicialmente traçando um paralelo em cima da atualidade contemporânea, pode-se retirar um abstrato, notável através dos Meios de Comunicação de Massa, que a Ética Profissional vem sendo algo muito discutido e alvo conturbado na política brasileira, que diversas noticias nos rodeiam evidenciadas pelos holofotes neste primeiro semestre de 2012:

Segundo afirmar no livro de (Ortega y Gasset; ano 2006, p.ro), em que expõe um trecho: Mas se houvésseis nascido naquele tempo, por mais que olhásseis nascido naquele tempo, por mais que olhásseis ao vosso redor não tereis reconhecido no trabalho desse homem aquilo que hoje denominamos ser bibliotecários, mas sua conduta vos teria parecido o que com efeito, era uma peculiaridade individual, um comportamento personalíssimo uma inclinação intransferivelmente inerente aquele homem, como o timbre de sua voz ou harmonia de seus gestos. A prova disso é que, ao morrer esse homem, sua ocupação morria com ele, não continuava de pé além da vida individual que a exerceu.

Ou seja, Ortega y Gasset, quer dizer, que o indivíduo naquele tempo nascia com a conduta e morria com a mesma, que levo a entra em acordo, em que, se o individuo tem uma boa base de vida e uma alto nível de instrução, possivelmente terá princípios e virtudes inalienáveis que poderá considerar para não errar na vida e profissionalmente, claro que deixo claro que não é uma regra, pois há pessoas com os mesmos critérios já ditos que acabam quebrando a ética profissional de diversas categorias profissionais, já também não deixando de errar na própria vida.

\section{MARCO HISTÓRICO DA IMPORTÂNCIA DO PAPEL DO PROFISSIONAL DA INFORMAÇÃO NO BRASIL}

Com base nas diversas leituras adquiras, gero um conhecimento entendido, que diversos fatores históricos que merecem serem destacado. Ser começarmos transcorrer a história dos bibliotecários numa biblioteca, notaremos que não é fácil entender que, desde 

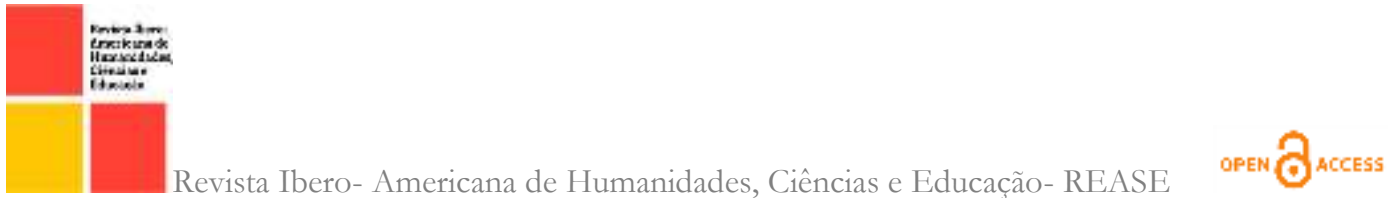

daquela época, já existia biblioteca e indivíduos empenhados em destacar a educação no Brasil. De certo, um fato interessante é que no Brasil, desde o século XVI, já havia a existência e criação de bibliotecas no Brasil, os jesuítas que induziam, através das escolas Jesuíticas da época catequização e alfabetizar e conduzi-lo leitores. Então, é notado que no Brasil já existiam guardiães de livros e educadores que preocupavam em evangelizar e, ao mesmo tempo domesticar e educar o povo daquela época. Com o passar do tempo a biblioteca evoluiu muito. E hoje, deixa de existir o denominado termo guardião ou curado de livros de certa forma no Brasil, trazendo na sua linhagem uma bagagem de repercussões e alguns reflexos, que permeia esse profissional empenhado que hoje, nos moldes do Século XXI é uma profissão oficializada, porém pouco conhecida no Brasil.

No Brasil I. - curso de biblioteconomia, foi oferecido pela biblioteca nacional em I915, sendo estruturado em 1971, mas possui traços de uma grande influência da França, na formação deste profissional da informação, naquela época que era um profissional bibliotecário humanista. Já em (1930 - 1960), tinha um modelo de ensino da era dos norteamericanos, que influenciava na forma técnica, os moldes de aprendizagem do bibliotecário. Sendo que está forma tecnicista da biblioteconomia, marcou a formação do bibliotecário no Brasil. Já na década de 50 e 6o, houve neste I. ${ }^{\circ}$ Ciclo desta primeira década o impulsionamento da biblioteconomia como o para o profissional de nível superior. Há também o então, 2. . Ciclo da segunda década já citado.

Outro que merece ser lembrado na história do bibliotecário, é que ocorreu um marco no Brasil, que foi a publicação e regulamentação da Lei 4084/62, que com o Decreto n. ${ }^{\circ} 5725 / 656$; aprovando a biblioteconomia como profissão liberal, técnica de nível superior e também outro ponto principal, foi que o Código de Ética (C.F. Resolução 327/86 do $\mathrm{CBF}$ ), aprovado na década de 8 o.

Podemos dizer assim, que a década de 50 e 6o, foi de grande importância para o profissional bibliotecário em formas de alcance de objetivos profissionais para definir e garantir espaço no mercado de trabalho e entre outros. Outro ponto que merece salientar é que no período das décadas de 50 e 6o, houve também um considerável crescimento do número de bibliotecários, fora de alguns estados pioneiros como (SP, RJ E BA). 
Os demais bibliotecários que se formaram na década de 5o, entre as io instituições de Biblioteconomia no Brasil, eram direcionadas a: organizar a biblioteca, montar bibliotecas, incitar e incentivar à prática de leitura e uso nas bibliotecas, formar coleções bibliográficas e gerar serviços de busca da informação ao usuário.

\section{O PROFISSIONAL DA INFORMAÇÃO MEDIANTE SUAS ADAPTAÇÕES NO BRASIL; ACOMPANHAR OS SURGIMENTO DOS SUPORTES DE INFORMAÇÃO}

Conforme estamos vivendo nesta era da informação, aonde, está tudo em tempo real, integral e instantâneo, e que por novos suportes tecnológicos, ou seja a (Tecnologia da Informação). A informação tem acompanhado esses novos meios, pelas transformações dos suportes e dados para chegar a então informação. Em que, essa informação fica dispersa e o profissional da Informação, o bibliotecário acaba tornando indispensável. Com esse aumento de bibliotecários e a transformação sofrida na área da Ciência, Tecnologia e a Aglutinação da documentação na biblioteconomia no Brasil. Nisso leva a requerer um bibliotecário de constante mudança, integrativo e ser apto a sofrer transformações e adaptar-lhes, atualizando profissionalmente por uma especialização, ou seja, o profissional não deve exclusivamente prender-se ao processamento técnico numa biblioteca, ele é um agregador de valores, que deve ser um profissional moderno, apto a sofrer transformação conforme as mudanças que estarão a surgir, contudo, podemos empregar esse termo de profissional Moderno, pois é um estereótipo profissional, que deve entrar em adaptação para não estagnar no tempo, proporcionando e oferecer serviços de qualidade ao usuário. Mas, para isso, o breve autor, assim salienta que:

(Maria Lígia Pomim Valetim; 2002, p.I19), o profissional da informação precisa buscar informação e conhecimento de forma continua, pois estes são os mais valiosos recursos estratégicos. Investir nisso é muito importante para o crescimento profissional. Por uma questão de atitudes profundamente arraigadas, a maioria dos profissionais espera que a organização faça isso, isto é , seja a única responsável pela sua educação continuada. $\mathrm{O}$ profissional deve ter consciência de que a responsabilidade pela sua educação continuada, ou seja, a informação e o conhecimento dentro de um prisma mais adequado: como investimento pessoal; é da organização em que atua, mas não só dela é também dele mesmo.

Fato interessante ressaltado, que a educação é algo fundamental para o crescimento profissional de um indivíduo que queira ser um profissional de renome, dar condições para 
conseguirmos chegar a um objetivo, isso influenciará na fase de constituição de bibliotecário que apresentará serviços e produtos de qualidade a um usuário. Não importa as dificuldades que apareceram, o fato que é devemos atacar o problema sem saber a causa. Em outro dado momento, o autor trouxe com uma citação, um fato polêmico e interessante, e que gera uma reflexão legal, é que:

(Plácido Costa; 2002, p.II4), que a formação que os profissionais recebem tende a tornar-se obsoleta no período de três a cinco anos, conforme revelam alguns estudos, $\mathrm{e}$ as contingências das atividades profissionais hoje, especialmente nas áreas relacionadas com a utilização das tecnologias, levam a que mesmo recém formados precisem rapidamente equacionar a necessidade de atualização continuada, para se manterem competitivos no mercado de trabalho.

\section{QUAL A IMPORTÂNCIA DAS TECNOLOGIAS DA INFORMAÇÃO PARA O PROFISSIONAL BIBLIOTECÁRIO}

As tecnologias da informação, tem uma importância, pois, é através do uso do computador, sendo um suporte, e dos recursos das telecomunicações para a armazenar e transmitir os dados pelas unidades de informação, que cresce a cada dia, que, aliás estamos na era da informação e não é a toa que a globalização tem um poder muito grande de influenciar o profissional da informação bibliotecário nesta jornada. Com o surgimento destas nova tecnologia da informação o profissional bibliotecário tem de adaptar com as inovações. Essa tecnologia facilitou, pois, o bibliotecário que tem o conhecimento dos meios virtuais de busca de informação, todo em suas mãos, este setor de busca é que localiza em questão de instante um livro nas estantes de uma biblioteca. Ou seja, o bibliotecário tem de está inteirado com a tecnologia, pois é necessário e preciso. Segunda, assim afirma:

(César Augusto Castro; 200o, p.22), que: A perspectiva engloba desde a formação até de estudos de mercado de trabalho. A técnica as formas de controle, processamento me armazenamento da informação e, também o uso das novas tecnologias e linguagens documentárias. Os modelos de influência evidenciam o currículo e a inserção política, social, cultural e educacional do bibliotecário. Já em outro momento autor, reitera que ;

(César Augusto Castro; 200o, p.134), que: $\mathrm{O}$ confronto do bibliotecário com outros profissionais se dá na medida em que o aparecimento de outros suportes do conhecimento necessários a sua formação o habilita a organizar bibliotecas, centro de documentação ou espaços onde haja 
essencialmente impressos, diga-se livros. O ideal seria instrumentalizá-los a manipular informações, independente do suporte no qual se encontre registrada. Este é um discurso comum entre os bibliotecários, porém na prática não se concretiza efetivamente, respeitando- se as devidas exceções.

Há uma certa consonância nas informações argumentadas. No entanto, é fácil compreender que a tecnologia com diversos suportes que se inovam, é algo necessário para vida do bibliotecário. Atualmente, vivemos num processo corriqueiro de informatização, que a sociedade também efetua parte desta mudança e transformação, por exemplo, que quem não faz parte deste processo está fora, descartada do contexto social e mundial, assim, como cada vez que corremos atrás suprir os próprios objetivos, o tempo fica mais escasso, em que, a cada dia que passa a "sociedade não é a mesma geração da de ontem ou de um tempo atrás”, por que tende a se transformar na medida que a informação avança, a sociedade também avança. Assim, como, com o tempo corrido, a maioria da sociedade tem o computador e a 'internet', como companheiro e como fonte de pesquisas; informações que devem ser filtradas e também o moderno pagamento pelos de site de bancos com o dinheiro de plástico (Cartão de Crédito ou Cartão de Débito), através da 'internet' ('online'), compras através de um simples clique, sem sair de casa. Com relação ao processamento de dados, já citado; devido à alta demanda de coleta de dados, foi preciso com tempo, a adaptação e ampliação de 'software' para processar em volume significativo de análises qualitativas e quantitativas.

Ou seja, na medida que gera muito informação em alta demanda, esses dados tem que tem uma certa eficiência de armazenamento. Assim, a cada dia novos suportes tecnológicos surgem e ficam mais usuais. O ser humano, passou a ter diversas facilidades em sua mão, agora o problema maior será de ter a dada possibilidade de filtrar as informações que pode ser acessada de qualquer suporte. Aqui entra o papel para ser assumido do profissional bibliotecário. $O$ autor, até o momento que relata sobre a suposições que o bibliotecário se auto-avaliam entendo, já no momento que conduz um simples comentário, entro em discordância, pois seria uma pura ignorância pensar desta forma que nem está no problema b). No meu haver não deixais de pensar que o bibliotecário é essencial para um crescimento intelectual de uma sociedade, há muitas informações, devido o grande fluxo de informações geradas, de imediato irá precisar de ser 
filtrada, e quem terá a alçada para ficar diante dessa situação. Então o autor leva a pensar na:

(Francisco das Chagas de Souza; 2006, p.27), A discussão que toma a identidade profissional como o problema a ser compreendido coloca a questão Quem somos? A resposta a esta questão tem sido cada vez mais cobrada dos próprios bibliotecários. Esse debate transmite, em várias circunstâncias, duas possíveis ideias: a) o bibliotecário tem uma completa ignorância de que sua imagem profissional é construída na interação social, por um processo de objetivação da realidade, assimilada como valor e então subjetivada e expressa como representação e, portanto, manifestando a percepção social que o próprio bibliotecário tem do valor do papel que exerce na sociedade e b) a sociedade não precisa da presença desse bibliotecário; ele é um impostor.

Nesta contemporaneidade, tudo está rápido em constante mudança, muita informação é lançada e gerada a cada dia, ou seja, pelos Meios de Comunicações de Massa, ou através de livros, ou pela internet que mais cresce nas mãos dessa juventude globalizada, essa transformação que chega a influenciar o "homem" na forma de raciocinar, de relacionar e comunicar. Com isso, surgir a requerer o profissional bibliotecário que ira ser o intermediador ou mediador da informação até chega a mão do usuário, ou leitor. Nesses tempos modernos de grande "fluxo de informação", com grande produção de informação e surgimentos de novas tecnologias. Fato importante e vale ressaltar, é que:

No ano de 1935, o filósofo (Ortega y Gassset; 2006, p.40-45), ressalta, sem grande discurso do livro : "Missão do Bibliotecário", ficou tratado um ponto de grande relevância, logo reescrevo dois importantes pontos que seriam :I $\mathrm{o}$ Já tem livros demais, que são produzidos constantemente; $2^{\underline{0}}$ Tendo muitos livros produzidos o mercado passa a produzir cada vez mais;

Contudo, isso, compreendo que o bibliotecário ficará diante de um sério problema, sendo a explosão dessa informação produzida descontrolada. Já a outra autora efetua um breve e importante comentário:

(Miriam Vieira da Cunha; 1999, p.5) As mudanças que estamos vivenciando na profissão e nas unidades de informação, no contato com os usuários - reforçadas e impulsionadas pelas novas tecnologias e principalmente pela Internet - representam um desafio sem precedentes. Além de trabalharmos em bibliotecas sem muros, cada vez mais conectados com o mundo, com todos os setores das instituições onde trabalhamos e com outras unidades de informação, estabelecendo pontes ou redes formais ou informais, nossa valorização profissional depende muito de uma cabeça aberta - sem muros - com capacidade de buscar o 
novo, de ter curiosidade, de estar em contato com outros profissionais e principalmente de não ter medo de inovar

O fato que vale bater no ponto de partida, fazendo uma relação da data da publicação do da palestra e até, é que se nota, que cerca de mais de 60 anos atrás o pensante Ortega y Gasset, já fazia uma previsão desse descontrole e que seria uma missão de grande competência do profissional bibliotecário, com base nessa grande e constante produção de "fluxo de informação" Levando, a tentar entender o grande fluxo de informação, o que leva a isso? Podemos iniciar explicado partindo da globalização, que tem o papel de interligar e integrar corriqueiramente todo o mundo, quebrando barreiras. Em que, há uma certa exigência de profissionais empenhados, qualificados para acompanhar a constante mudança da informação, e ter uma perícia e prática para ter uma iniciativa que também esteja apto a ter um bom relacionamento entre as pessoas.

Com os moldes dos anos 6o, depois da certa Revolução Tecnológica, houve de carta forma, um alavancamento significado nos sistemas de informação, como (o aumento e crescimento de rede e de sistemas de informação, que hoje facilita o serviço e produto, que o profissional bibliotecário, disponibiliza dentro de um setor da biblioteca, centro de documentação e/ou unidade de informação, que mais usual pelas organizações, hoje tem que haver uma integração dos setores de uma instituição, que lida com o processo de divulgação e processamento desta informação, que de certa forma no caso da unidade de informação, pode partir de uma parte, que seja de um setor de: (Recursos Humanos, contabilidade, 'marketing', administração, secretária e entre outros departamentos, dentro de uma empresa ou organização.

Por isso, o profissional da informação, de uma forma mais ampla, como já dito integra a sua unidade da informação, com as demais unidades, que quando a informação é buscada, analisada, e difundida, evita um duplo trabalho e retrabalho, e isso é custo, pois, as empresas hoje trabalham em função do tempo, e tempo dinheiro. No entanto, essa necessidade de disponibilizar ao usuário a informação, e venha agregar valores e somar é um dos vários objetivos enfrentado pelo profissional bibliotecário, que, aliás com o advento da internet, existiu muita informação disponível, e o bibliotecário tem que influenciar a na recepção dessas informações, indicando fontes de informação certa e segura, e a internet tem como base a forma de troca de informação, e essa troca há uma 
crescente obtenção de geração de mais informação. Relativamente, há uma certa distância em relação, e ao conhecimento e perícia do profissional, que, entretanto esse processo de formação acadêmica, que o formando leva a ter e gerar uma construção de apoio como um referencial da identidade do profissional bibliotecário.

O interessante é que o bibliotecário pioneiro, neste tempo de mudança-(Tempo Moderno) no Brasil é considerado a ser um generalista, ou seja, que domina através da informação, todas as áreas do conhecimento. Com todo esse gerado fluxo de informação, aqui entra: $O$ valor da consciência da informação na globalização, em plena trajetória da vida. Que necessariamente demonstra, que não adianta fugir da informação, que ela esta acompanhando cada indivíduo desde o próprio momento que nasce, carregando dados informacionais até a morte.

A então autora vai longe e confirma que: Outro ponto crucial, é o estudo através da leitura, que advém a informação, que gera na ampla trajetória o conhecimento, que deve ser repassado, passando para assim, ocorre o compartilhamento e disseminação da informação. Pois, desde esse indivíduo passa a correr atrás do próprio objetivo, a nação passa a desenvolver e progredir também. Mesmo que na maioria das vezes um estado (nação), não assegure direitos sociais e políticos (educação, saúde e segurança), o indivíduo não deve estagnar, tem que ter determinação e força de vontade para superar esses momentos inoportunos. Com valor e liberdade de satisfação, pelo ato de informação, o indivíduo que busca a informação tem poder e gerar conhecimento para o mundo.

\section{CONSIDERACÕES FINAIS}

Por isso, entendendo que profissional bibliotecário, é uma profissão possui seus contrastes. $\mathrm{O}$ artigo é bem explicativo, efetua uma reflexão e questionamentos do profissional bibliotecário no Brasil, a respeito das ocorridas transformações que estão surgindo e o mais difícil é a questão da adaptação as essas mudanças, que seria pela tecnologia da informação, que será enfrentada pelo profissional da informação, sem nenhuma repulsão. Desatacamos a ética para ser seguida e aplicada pelo profissional da informação, por conseguinte indica a importância desses princípios morais, para a formação do profissional bibliotecário. Entende-se, que será de grande importância para a mediação da informação. Indicando fontes confiáveis e segura para o usuário que venha precisar de um serviço de informação. Compreendo que bibliotecário, muito contribui para 
agregar valores na educação, que contribui na geração de uma sociedade despertar e consciente, através da informação. Disponibilizada por um profissional bibliotecário.

Entendo que a globalização está por detrás de toda esse contraste profissional do bibliotecário. Então, a informação é assim como os suportes tecnológicos, também é tendenciosa e sofre mudanças constantes.

\section{REFERÊNCIA BIBLIOGRÁFICAS}

CASTRO, César Augusto. História da Biblioteconomia Brasileira: perspectivas histórica. Brasília: Thesaurus Editora, 2000.287p

GASSET, José Ortega y. Missão do bibliotecário. Brasília: Briquet de Lemos, 2006. p.82p VALENTIM, Maria Lígia(Org.).Formação do Profissional da Informação. São Paulo: Editora Polis.2002.148p

FERREIRA, Aurélio Buarque de Holanda. Mini Aurélio Escolar: Século XXI. Editora Nova Fronteira,2000.79op

CUNHA, Mirian Vieira da. O Profissional da Informação e o Mercado de Trabalho. Santa Catarina, mar.1999, v.I, Disponível em http://www.ies.ufpb.br/ojs/index.php/ies/article/view/347/269>; acesso numa QuartaFeira, I7 de Abril de 2013, às 09:18

SOUZA, Francisco das Chagas de. A Formação Acadêmica de Bibliotecário e Cientistas da Informação e Sua Visibilidade, Identidade e Reconhecimento Social no Brasil. João Pessoa, jan./ jun.2006, v.I6, n.I. Disponível em: < http://www.biblionline.ufpb.br/ojs2/index.php/ies/article/view/439/ı49I>; acesso numa Quinta-Feira, o9 de maio de 2013, às 12:19

\section{REFERÊNCIA (SITE)}

Disponível em: 〈http:// www.crb8.org.br/institucional.php > Acesso em 06/05/2013, às I8:10 